\title{
PERFIL DE ÁCIDOS GRAXOS E FRAÇÕES PROTEICAS DO LEITE DE CABRA
}

\section{Goat milk fatty acids profile and protein fractions}

\author{
Grazielly de Jesus Silval ${ }^{1}$ Ben-Hur Ramos Ferreira Gonçalves ${ }^{1}$, Daniele Gomes Conceição ${ }^{I}$, \\ Silvania Farias Oliveira Pontes ${ }^{I}$, Sibelli Passini Barbosa Ferrão ${ }^{{ }^{*}}$
}

\section{RESUMO}

Objetivou-se realizar um estudo sobre o perfil de ácidos graxos e frações proteicas do leite de cabra. A principal característica da gordura desse leite é o alto teor de ácidos graxos de cadeia curta e média, que tem pelo menos duas vezes mais ácidos graxos C4-C10 do que o leite de vaca. Esses ácidos graxos possuem metabolismo diferente dos ácidos graxos de cadeia longa. As proteínas do leite de cabra são constituídas em média de $71 \%$ de caseínas, $22 \%$ de proteínas do soro (proteínas solúveis) e 7\% de nitrogênio não proteico. Em comparação com o leite de vaca, o leite de cabra contém menos caseínas, mais proteínas séricas e mais nitrogênio não proteico. A identificação dos componentes do leite de cabra e a caracterização de suas propriedades poderão servir como ponto inicial para elaboração e implantação de programas para melhoria da qualidade do leite de cabra e seus derivados.

Palavras-chave: caprino; gordura; proteína.

\begin{abstract}
The aim of this study/reviewer was to evaluate the profile of fatty acids and protein fractions on the goat milk. The goat milk has as main characteristic the short and medium fatty acid chain (C4-C10) that is, at least as twice as much of that observed in cow milk. The protein fraction on the goat milk is composed in average by caseins $(71 \%)$, whey proteins, $22 \%$ (soluble proteins) and non-proteic nitrogen (7\%). When compared to cow's milk, the goat's milk has less casein, more serum proteins and non-proteic nitrogen. Compared with cow milk, goat milk contains less
\end{abstract}

1 Universidade Estadual do Sudoeste da Bahia, Campus Universitário Juvino Oliveira, 45700-000, Itapetinga, BA, Brasil. E-mail: sibpass@yahoo.com.br

* Autor para correspondência.

Recebido / Received: 21/03/2016

Aprovado / Approved: 22/08/2016 
casein, more serum proteins and non-protein nitrogen. The identification of goat milk components and the characterization of their properties may serve for developing and implementing programs to improve the quality of milk and dairy products.

Keywords: goat; fat; protein.

\section{INTRODUÇÃO}

O leite de cabra é um líquido branco, viscoso, com odor característico e que apresenta propriedades físico-químicas semelhantes ao leite de vaca. Entretanto possui algumas peculiaridades como: menor diâmetro dos glóbulos de gordura, o que lhe confere maior digestibilidade; e presença de baixos níveis da fração protéica $\alpha_{\mathrm{s} 1}$ - caseína, indicado como um dos principais agentes causadores da alergia ao leite de vacas (JACOPINI et al., 2011).

A alergia à proteína do leite de vaca (APLV) acomete mais crianças de até 3 anos de vida e muitas vezes é de difícil diagnóstico. Segundo Ballabio (2014), o leite de outras espécies tem sido sugerido como uma alternativa nutricional ao leite de vaca, mesmo que alguns estudos clínicos tenham mostrado risco elevado de reatividade cruzada com o leite bovino. Nas espécies de cabra, a $\alpha_{\mathrm{s} 1}$-caseína $\left(\alpha_{\mathrm{s} 1}-\mathrm{CN}\right)$, codificada pelo gene CSN1S1, é caracterizada por extensos polimorfismos qualitativos e quantitativos, e alguns alelos estão associados com nenhuma ou reduzida expressão da proteína reativa específica.

O leite caprino apresenta composição química constituída de proteínas de alto valor biológico e ácidos graxos essenciais, além de seu elevado conteúdo mineral e vitamínico, o que o qualifica como alimento de boas características nutricionais. Devido a estes fatores, crianças, idosos e/ou pessoas alérgicas ao leite de outras espécies são os maiores consumidores do leite de cabra (COSTA et al., 2009; PEREIRA et al., 2009).

Além de possuir peculiaridades que o diferenciam do leite de outras espécies, a composição do leite de cabra também varia de acordo com a raça, alimentação, condições ambientais, estação do ano, estágio de lactação, quantidade de leite produzido e fisiologia individual do animal (PARQUE et al., 2007). Sendo que a qualidade da dieta associada ao manejo alimentar é determinante na produção, composição e qualidade deste leite (SILVA et al., 2009; SLAČANAC et al., 2010).

Apesar de suas qualidades, o leite de cabra e seus derivados apresentam-se ainda com pouca expressão no mercado nacional, além de pouca literatura em nosso país no que se refere ao seu processamento, qualidade tecnológica, propriedades físicas e químicas e aceitação destes produtos. No setor produtivo, o problema de irregularidade na oferta também é uma realidade, o que resulta em insatisfação da indústria e do consumidor, pois o produto adquirido muitas vezes não atende às expectativas. $\mathrm{O}$ conhecimento da composição e do efeito destes componentes do leite nas propriedades tecnológicas dos derivados e na saúde do homem podem ser fatores que agregariam valor aos derivados e impulsionariam o mercado produtor (COSTA et al., 2009; EMBRAPA, 2013).

Com isso, o presente artigo de revisão tem por objetivo realizar um estudo sobre o perfil de ácidos graxos e frações proteicas do leite de cabra.

\section{REFERENCIAL TEÓRICO}

\section{Caprinocultura e o leite de cabra}

Segundo dados da Organização das Nações Unidas para Agricultura e Alimentação 
(FAO, 2014), em 2012, o rebanho caprino mundial foi de, aproximadamente, 996 milhões de cabeças, com forte concentração nos países subdesenvolvidos e em desenvolvimento. $\mathrm{O}$ Brasil é o $17^{\circ}$ criador mundial, com cerca de 8.646 milhões de cabeças, produzindo anualmente 150 milhões de litros de leite de cabra, sendo o país de maior produção no continente americano.

A caprinocultura leiteira se caracteriza como atividade importante para a região Nordeste do Brasil, contribuindo para geração de emprego e renda, principalmente para as classes sociais mais necessitadas (EMBRAPA, 2013). Segundo o Instituto Brasileiro de Geografia e Estatística (IBGE, 2014), em 2012, o Nordeste foi a região brasileira com o maior efetivo desta espécie, com cerca de 7.841 milhões de cabeças. Entretanto, alguns fatores limitam o aumento da produtividade e distribuição do leite caprino durante o decorrer das épocas do ano. Esses problemas ocorrem não somente nas regiões brasileiras, mas também em diversos países que desenvolvem a caprinocultura leiteira. Dentre os fatores que interferem na realização desta atividade destacam-se: o potencial genético dos rebanhos, a sazonalidade da produção, a qualidade das forrageiras tropicais utilizadas, o clima, manejo, intervalo de partos, a idade ao primeiro parto, o controle das enfermidades, gerenciamento, nutrição e alimentação dos rebanhos, entre outros (GONÇALVES et al., 2008).

Atualmente, o grande desafio dos produtores de leite de cabra do semiárido brasileiro é a ampliação do mercado. Programas governamentais são necessários e auxiliam no desenvolvimento da caprinocultura leiteira na região, por meio de políticas de incentivo como a distribuição de animais para formação de rebanhos e compra do leite produzido para posterior industrialização. A transformação do leite de cabra em produtos lácteos mostra-se como alternativa viável para amenizar os problemas referentes à caprinocultura leiteira, pois é uma forma de aumentar o tempo de conservação do leite, contribuir para o bem-estar econômico do produtor, agregar valor e ampliar o mercado consumidor (EMBRAPA, 2013; SANTOS et al., 2016).

De acordo com o Regulamento Técnico de Produção, Identidade e Qualidade, o leite de cabra é definido como o produto oriundo da ordenha completa, ininterrupta, em condições de higiene, de animais da espécie caprina sadios, bem alimentados e descansados, com requisitos mínimos de composição química e físico-química. O percentual de gordura deve ser o original, ou seja, em hipótese alguma o teor de matéria gorda pode ser extraído do leite fora da indústria de laticínios; deve possuir valores mínimos de $8,2 \%$ de sólidos não gordurosos, $2,8 \%$ de proteína bruta e $4,3 \%$ de lactose (BRASIL, 2000).

De acordo com a composição química, o leite de cabra é similar ao leite de vaca, mas difere do mesmo em algumas formas e concentrações de nutrientes, tais como: maior digestibilidade, alcalinidade, capacidade tamponante e características medicinais para a nutrição humana, relacionadas aos problemas de alergia alimentar (AMARAL et al., 2011).

\section{Composição em ácidos graxos}

A principal característica da gordura do leite de pequenos ruminantes é o alto teor de ácidos graxos de cadeia curta e média (MCFA), especialmente em leite de cabras, apresentando um metabolismo diferente dos ácidos graxos de cadeia longa. MCFA podem ser liberados de triacilgliceróis pela lipase gástrica do estômago e lipase pancreática, e serem absorvidos diretamente pelas células intestinais, sem esterificação, e transportados principalmente pela veia porta (dependendo do comprimento da cadeia e posição inicial dos triacilgliceróis) para o fígado, 
onde são rapidamente oxidados (RAYNALLJUTOVAC et al., 2008).

O leite caprino possui peculiaridades funcionais quando incluído na alimentação humana, comparado ao leite de vaca, podendo destacar a digestibilidade (COSTA et al., 2009). A melhor digestibilidade do leite de cabra em relação ao leite bovino ocorre devido a fatores como o alto conteúdo de ácidos graxos de cadeia curta (compostos de 4 a 10 átomos de carbono). Os glóbulos de gordura no leite caprino são menores em tamanho, promovendo maior área superficial para degradação enzimática, o que confere maior eficiência na absorção e digestão pelo organismo humano (AMARAL et al., 2011).

Há um entendimento dominante de que a gordura é o componente do leite que mais sofre influência da alimentação. Essas alterações não ocorrem somente com relação a sua concentração, mas também na composição dos ácidos graxos (Tabela 1) (LUCAS et al., 2008).

Os ácidos butírico ( $\mathrm{C} 4: 0)$, caproico (C6:0), caprílico (C8:0) e cáprico (C10:0) (Tabela 1) são típicos do leite caprino e fazem com que os produtos derivados apresentem sabor e aroma característicos, tornando-os sensorialmente distintos (SANZ SAMPELAYO et al., 2007; VIEITEZ et al., 2016). Já os ácidos graxos saturados, são característicos do leite bovino, como o ácido palmítico (C16:0) e o ácido oleico (C18:1) (EIFERT et al., 2006).

Além do teor de sólidos totais, a manipulação do perfil dos ácidos graxos do leite

Tabela 1 - Composição aproximada (\%) dos principais ácidos graxos presentes nos leites de vaca e cabra

\begin{tabular}{ccc}
\hline Ácido graxo & Vaca & Cabra \\
\hline Ácido butírico (C4:0) & 3,6 & 4,8 \\
Ácido caproico (C6:0) & 2,0 & 2,3 \\
Ácido caprílico (C8:0) & 1,3 & 2,7 \\
Ácido cáprico (C10:0) & 2,6 & 9,5 \\
\hline Total Cadeia Curta & 9,5 & 19,3 \\
\hline Ácido láurico (C12:0) & 3,0 & 4,4 \\
Ácido mirístico (C14:0) & 11,2 & 10,0 \\
Ácido palmítico (C16:0) & 29,0 & 25,0 \\
Ácido esteárico (C18:0) & 13,0 & 9,3 \\
\hline Total Saturado & 56,2 & 48,7 \\
\hline Ácido palmitoleico (C16:1) & 2,6 & 2,0 \\
Ácido oleico (C18:1) & 24,4 & 21,0 \\
\hline C18:1 Trans & 3,0 & - \\
\hline Total monoinsaturado & 30,0 & 23,0 \\
Ácido linoleico (C18:2) & 2,6 & 2,3 \\
Ácido linolênico (C18:3) & 1,7 & 1,0 \\
\hline Total poli-insaturado & 4,3 & 3,3 \\
\hline
\end{tabular}

FONTE: adaptado de Eifert et al. (2006), Vieitez et al. (2016). 
pode ser um recurso para melhorar a imagem do leite e derivados junto aos consumidores que buscam produtos nutricionalmente mais saudáveis, que disponham de substâncias com propriedades comprovadamente terapêuticas (MAIA et al., 2006). Além de fornecer energia, os ácidos graxos oriundos da dieta atuam na regulação do metabolismo animal, cujo papel metabólico está relacionado com aspectos da sua estrutura molecular, tais como: comprimento da cadeia, presença de duplas ligações, posição e isomeria das duplas ligações. No caso específico de ácidos graxos poliinsaturados, estes têm maior impacto sobre a atividade e expressão gênica de enzimas relacionadas com o metabolismo de carboidratos, lipídios (SALTER; TARLING, 2007) e ciclo celular (MIGLIETTA et al., 2006).

Fatores como clima, raça, indivíduo e estágio de lactação são relevantes, mas o manejo alimentar tem sido considerado um fator preponderante na manipulação dos componentes do leite (SANTOS et al., 2016). Dados mostram que cabras alimentadas com altos níveis de forragens produzem conteúdos mais elevados dos ácidos graxos C4:0, C6:0, C18:0, C18:1, C18:3 e C20:0, quando comparados a animais da mesma espécie e que não receberam esta alimentação. Entretanto, níveis elevados de alfafa podem produzir valores mais baixos de trans-C18:1. Assim, diminuindo-se o conteúdo de fibras e aumentando-se grãos na ração diária dos animais, produzem-se teores mais altos deste ácido graxo no leite (COSTA et al., 2009).

Além de sua importância nutricional e terapêutica, esses lipídios possuem impacto tecnológico, uma vez que influenciam no sabor e aroma específicos dos produtos lácteos caprinos (PARK et al., 2007). Devido às suas características nutricionais, os pesquisadores têm tentado melhorar as características físicoquímicas do leite de cabra, especialmente através da indução de mudanças, como adição de diferentes fontes de gordura na alimentação de cabras leiteiras (QUEIROGA et al., 2007).

Estudos têm relatado efeitos positivos da suplementação lipídica sobre a qualidade do leite de cabras. Sanz Sampelayo et al. (2007) citam que a suplementação lipídica em cabras leiteiras não causa mudanças no consumo de energia ou na produção de leite, mas aumenta significativamente o teor de gordura do leite na maioria dos casos.

Santos et al. (2012) observaram que dietas de cabras com suplementação de óleo de soja aumentaram o teor de gordura e sólidos totais do leite. Resultados semelhantes a respeito das mudanças na composição do leite, como consequência da suplementação com óleo de soja na dieta de cabras foram relatados por Bouattour et al. (2008), com particular aumento do nível de gordura e manutenção do teor de proteínas.

Pereira et al. (2010) relataram que a inclusão de óleo de rícino como um suplemento na alimentação de cabras leiteiras modificou os teores da composição química do leite, em especial os níveis de gordura, além de acentuar o sabor rançoso no perfil sensorial. Em contraste, a suplementação de óleos vegetais na dieta não afetou as características sensoriais de queijo de cabra, o que pode ter ocorrido devido a fatores tecnológicos resultantes do processo de fabricação.

Além de alterar a produção e composição do leite em sólidos totais, suplementos lipídicos possibilitam a manipulação da composição em ácidos graxos da gordura do leite, sendo amplamente estudada a diminuição nos teores de ácidos graxos saturados e aumento nos ácidos graxos insaturados, os quais apresentam uma série de benefícios comprovados para a saúde humana (MAIA et al., 2006; HOSAM, 2011).

Segundo Costa et al. (2009), as alterações que ocorrem no leite com relação à concentração da gordura devido à alimentação também influenciam a composição dos ácidos graxos. O comprimento da cadeia carbônica (cadeia curta ou longa), grau de saturação 
(saturado ou poliinsaturado) e isomeria geométrica (cis ou trans) dos ácidos graxos exercem mudanças nas propriedades tecnológicas da gordura como a textura e o aroma da manteiga e queijo, em razão dos diferentes pontos de fusão desses componentes.

Raynal-Ljutovac et al. (2008) avaliaram a composição de ácidos graxos de amostras de leite e queijos de leite de pequenos ruminantes (Roquefort e Ossau-Iraty) e os resultados mostraram que o processamento dos queijos não modificou o perfil de ácidos graxos, não havendo diferença significativa entre os ácidos graxos observados no leite e nos queijos processados a partir dele.

Assim, como a alimentação oferecida aos caprinos pode alterar a composição e as características sensoriais do leite, essa prática de manipulação na dieta oferecida aos animais torna-se importante ferramenta para produtores direcionarem as características fisíco-químicas desejadas na sua produção leiteira.

\section{Frações proteicas do leite}

As principais proteínas presentes no leite de cabra podem ser divididas em dois grupos
(Tabela 2), sendo o primeiro constituído pelas caseínas na forma de micelas $\left(\alpha_{\mathrm{s} 1}\right.$-caseína, $\alpha_{\mathrm{s} 2}$-caseína, $\beta$-caseína e $\kappa$-caseína), representando, em média, $80 \%$ das proteínas, e o segundo grupo se refere às proteínas solúveis do soro, $\alpha$-lactoalbumina, $\beta$-lactoglobulina, albuminas séricas e imunoglobulinas. Além disso, outros grupos de proteínas solúveis menos abundantes também podem ser encontrados, como lactoferrinas, glicoproteínas e enzimas (PARK et al., 2007; RONCADA et al., 2012).

Semelhante ao teor de gordura, as proteínas do leite de cabra exercem influência sobre a digestibilidade do mesmo. Valores mais baixos de $\alpha_{\mathrm{s} 1}$-caseína encontrados para algumas raças e genótipos diferentes (Tabela 2), quando comparado ao leite bovino, favorecem a formação de coágulos finos e suaves, sendo atacados mais facilmente e rapidamente no estômago por enzimas proteolíticas. Este fato facilita o processo digestivo e reduz problemas relacionados à alergia para alguns indivíduos, pois o tempo necessário para a alergia desaparecer ou apresentar sinais de melhora vai depender da severidade da reação inicial (GÓMEZ-RUIZ et al., 2004; BIDAT, 2010).

Tabela 2 - Composição média das proteínas dos leites de cabra e vaca

\begin{tabular}{ccc}
\hline & Leite de Cabra $(\mathrm{g} / \mathrm{L})$ & Leite de Vaca $(\mathrm{g} / \mathrm{L})$ \\
\hline Proteínas Totais & $28-32$ & $32-34$ \\
Caseínas & $22-28$ & $26-37$ \\
$\alpha_{\text {s1 }}$-caseína & $1,2-10$ & $11-15$ \\
$\alpha_{\text {s2 }}$-caseína & $1,0-3,0$ & $3-4$ \\
$\beta$-caseína & 11 & $9-11$ \\
K-caseína & 4 & $2-4$ \\
Proteínas do Soro & $5,5-6,5$ & $5,8-6,5$ \\
$\alpha$-lactoalbumina & 1,2 & $0,6-1,5$ \\
$\beta$-lactoglobulina & 3,1 & $3-4$ \\
Imunoglobulina & 1,0 & 1,0 \\
\hline
\end{tabular}

FONTE: adaptado de Gómez-Ruiz et al. (2004), Sgarbieri et al. (2005), Jacopini et al. (2011). 
As proteínas do leite de cabra ocorrem em duas fases distintas: a) uma fase variável, composta de caseínas na forma de micelas, medindo cerca de $190 \mathrm{~nm}$ de diâmetro, interligadas por fosfato de cálcio e pequenas quantidades de magnésio, sódio, potássio e citrato; b) uma fase solúvel, composta por proteínas do soro. A caseína se precipita em $\mathrm{pH}$ em torno de 4,6 a temperatura ambiente, enquanto as proteínas do soro ( $\beta$-lactoglobulina, $\alpha$-lactoalbumina e albumina do soro sanguíneo) sob as mesmas condições, permanecem solúveis (PARK et al., 2007).

Segundo Greppi et al. (2008), a fração de caseína do leite de cabra, subdividida em $\alpha_{\mathrm{s} 1}, \alpha_{\mathrm{s} 2}, \beta$ e K-caseína, se apresenta em um complexo sistema micelar em proporções aproximadas de 1:2:5:2, respectivamente, sendo considerado rico em $\beta$-caseína e pobre em $\alpha_{\mathrm{s} 1}$-caseína. Outra característica é um raro e complexo polimorfismo da $\alpha_{\mathrm{s} 1}$-caseína, sendo que 7 alelos já foram identificados, dando origem a 6 diferentes variantes proteicas e 4 frações para $\alpha_{\mathrm{s} 1}$-caseína. Os alelos A, B e C estão relacionados com alta concentração de $\alpha_{\mathrm{s} 1}$-caseína.

A variação do conteúdo total de proteínas é bem conhecida, sendo que para leite de cabras é dependente do polimorfimo de $\alpha_{s 1}{ }^{-}$ caseína. Geralmente, o leite de cabra tem menos $\alpha_{\mathrm{s} 1}$-caseína do que outros ruminantes produtores de leite. Dependendo da frequência do alelo existente para $\alpha_{\mathrm{s} 1}$-caseína em cada raça, a proteína total pode variar. $\mathrm{O}$ conteúdo total de proteína pode variar de 2,6 g/L a 4,1 g/L para leite de cabra e de $4,7 \mathrm{~g} / \mathrm{L}$ a 7,2 $\mathrm{g} / \mathrm{L}$ para leite de ovelha, sendo que os principais fatores que afetam o teor de proteína são estágio de lactação, estação do ano, idade do animal e sistema de alimentação (RAYNAL-LJUTOVAC et al., 2008).

Em pequenos ruminantes, a organização da micela de caseína pode ser diferente e altamente mineralizada, além do tamanho da micela caprina ser significativamete maior do que a de bovinos e ovinos. Esta carac- terística tem uma relação direta com suas propriedades tecnológicas, mas a influência nutricional ainda não é bem conhecida. O teor de proteína total é um dos principais critérios de qualidade aplicado para o pagamento do leite de cabra em muitos países. Entretanto, a proporção de caseína (principal constituinte de queijos) e proteína total pode também variar entre espécies, animais e estágio de lactação. Já as proteínas do soro podem prejudicar a produção de queijos (relacionado ao rendimento do queijo e perda de soro, especialmente quando há tratamento térmico do leite), mas seu perfil de aminoácidos é de interesse devido ao elevado nível de aminoácidos essenciais (por exemplo, triptofano e lisina) (RAYNAL-LJUTOVAC et al., 2008).

As proteínas do leite, contêm sequências que, quando liberadas como peptídeos por hidrólise enzimática ou fermentação, exercem efeitos fisiológicos benéficos. Tais peptídeos bioativos exercem efeitos antitrombóticos, anti-hipertensivos, antioxidantes, imunomoduladores, entre outros (MADUREIRA et al., 2007; PHELAN et al., 2009). Peptídeos bioativos foram identificados principalmente a partir de leite de vaca, mas também as proteínas do leite de cabras incluem peptídeos com tais atividades (ATANASOVA; IVANOVA, 2010; ESPEJOCARPIO et al., 2013; LI et al., 2013).

Diversos estudos têm sido realizados para identificar a adulteração de queijos de cabra elaborados com a mistura de leite de ovelhas e, mais frequentemente, com leite de vaca (SHEEHAN et al., 2009).

Para identificar e quantificar as frações proteicas do leite e avaliar sua influência sobre a qualidade de derivados lácteos foram desenvolvidos nos últimos anos vários métodos analíticos baseados na análise das frações protéicas e peptídeos, dos quais os principais são os métodos de cromatográficos, imunológicos e eletroforéticos (EGITO et al., 2006). 


\section{Efeito dos componentes do leite para a saúde humana}

Nos últimos anos, devido à atenção que o consumidor tem dado para a relação entre dieta e saúde, há uma crescente preocupação com o conteúdo de gordura dos produtos de origem animal, principalmente em função da associação entre a composição em ácidos graxos e o risco de doenças coronarianas.

Os ácidos graxos caprílico e cáprico, e outros triacilgliceróis com ácidos graxos de cadeia média, têm sido usados em tratamentos específicos para pacientes que sofrem de vários problemas de má absorção, insuficiência pancreática, com déficit ou ausência de sais biliares. Estes ácidos graxos também têm sido usados em dietas de pacientes subnutridos, crianças prematuras e outras patologias, devido à grande facilidade em fornecer energia destes componentes (SANZ SAMPELAYO et al., 2007).

O leite de cabra também não possui aglutinina, proteína presente no leite bovino que une as partículas lipídicas, dificultando o processo digestivo. A digestão e absorção do leite de cabra são, então, duas vezes mais rápidas se comparadas ao leite de vaca, sendo indicado para crianças e idosos, ou ainda pessoas que apresentem problemas nutricionais ou gastrointestinais (PARK et al., 2007).

As propriedades nutricionais do sistema proteico do leite caprino têm sido estudadas, enfatizando que essas proteínas apresentam maior digestibilidade do que as do leite de vaca (PARK et al., 2007), já que sua proteólise no estômago é mais rápida, devido à sua menor quantidade da fração $\alpha_{\mathrm{s} 1}$-caseína (PARK, 2006). Como no leite humano, a caseína do leite caprino contém menos $\alpha_{\mathrm{s} 1}{ }^{-}$ caseína que, por sua vez, é responsável pela maioria das alergias associadas ao leite de vaca. Por essa razão, na maioria dos casos, pessoas alérgicas à proteína do leite bovino
(CMPA) respondem bem ao consumo de leite caprino (VILLALOBOS, 2005).

A hipersensibilidade às proteínas do leite de vaca é uma das principais causas de alergia provocada por alimentos. O leite de vaca possui mais de 20 proteínas alergênicas e que podem causar reações alérgicas nos indivíduos. Frações de caseína e $\alpha$-lactoalbumina são os compostos mais envolvidos em reações alérgicas. No leite de cabra, a deficiência da fração $\alpha_{\mathrm{s} 1}$-caseína, a principal caseína do leite de vaca, e uma maior fração de $\alpha_{\mathrm{s} 2}$-caseína tornam esse leite menos alergênico ou mesmo hipoalergênico, sendo uma alternativa em casos de alergia ao leite de vaca. No entanto, em alguns casos, o leite de cabra ou queijos fabricados a partir dele, também tem sido reconhecido como potencialmente alergênicos, apresentando reações ao teste de IgE específico (EL-AGAMI, 2007).

Segundo Albenzio (2012), a utilização do leite de cabra na alimentação de crianças com alergia à proteína do leite de vaca (APLV) é controverso, pois estudos sugerem que o leite de cabra do particular genótipo $\alpha_{s 1}-\mathrm{CN}$ pode ser utilizado na preparação de fórmulas modificadas para pacientes alérgicos, enquanto outros estudos demonstraram que o leite de cabra pode ser tão alérgico quanto o de vaca. Polimorfismos genéticos em cabras influenciam a presença e nível de síntese de cada fração das proteínas do leite exercendo importante papel na indução de diferentes graus de reação alérgica. Os baixos níveis de $\alpha_{\mathrm{s} 1}-\mathrm{CN}$ em leite de cabras fazem com que o seu perfil de caseínas seja mais próximo do leite humano em comparação ao leite de vaca. Assim, a utilização do leite oriundo de raças de cabras que possuem alelos fracos ou nulos para $\alpha_{\mathrm{s} 1}-\mathrm{CN}$ pode ser uma boa alternativa para a produção de leites para indivíduos alérgicos.

A alergia à proteína do leite de vaca ocorre quase sempre em crianças geneti- 
camente predispostas, afetando de forma significativa o bem-estar da criança e da família. Sua gênese está associada à introdução precoce do leite de vaca na alimentação de lactentes e desmame do leite materno também precoce (SLAČANAC et al., 2010).

O estudo das propriedades funcionais e nutricionais dos produtos lácteos é estratégia adequada para melhor aproveitamento do leite caprino, cujo papel funcional mais importante em relação ao bovino é a sua propriedade hipoalergênica (SANTILLO et al., 2009).

\section{CONSIDERAÇÕES FINAIS}

A identificação dos componentes do leite de cabra e a caracterização de suas propriedades podem servir como ponto inicial para elaboração e implantação de programas para melhoria da qualidade do leite e derivados, permitindo assim, ganhos de produtividade e oferta de alimentos seguros à população. Além disso, alternativas de processamento de derivados lácteos com qualidade comprovada criam novas possibilidades para o produtor e impulsionam o desenvolvimento do agronegócio, auxiliando na inserção e consolidação da caprinocultura como importante atividade econômica de desenvolvimento regional, bem como ampliação do mercado de derivados lácteos, não só em microrregiões, mas em todo o Nordeste brasileiro, impulsionando de maneira qualitativa a caprinocultura leiteira.

\section{REFERÊNCIAS}

ALBENZIO, M. et al. Differences in protein fraction from goat and cow milk and their role on cytokine production in children with cow's milk protein allergy. Small Ruminant Research, v. 105, n. 1, p. 202-205, 2012.

AMARAL, D. S. et al. Tendências de Consumo de leite de cabra: enfoque para a melhoria da qualidade. Revista Verde de Agroecologia e Desenvolvimento Sustentável, v. 6, n. 1, p. $39-42,2011$.

ATANASOVA, J.; IVANOVA, I. Antibacterial peptides from goat and sheep milk proteins. Biotechnology and Biotechnological Equipment, v. 24, n. 2, p. 1799-1803, 2010.

BALLABIO, C. et al. Goat milk allergenicity as a function of $\alpha_{\mathrm{s} 1}$-casein genetic polymorphism. Journal of Dairy Science, v. 94, n. 1, p. 998-1004, 2011.

BIDAT, E. L'allergie au lait de chèvre ou de brebis. Revue Française D'Allergologie, v. 50, n. 1, p. 128-131, 2010.

BOUATTOUR, M. A. et al. Feeding soybean oil to dairy goat's increases conjugated linoleic acid in milk. Journal of Dairy Science, v. 91, n. 6, p. 2399-2407, 2008.

BRASIL. Ministério da Agricultura, Pecuária e Abastecimento. Regulamento Técnico de produção, identidade e qualidade do leite de cabra. Instrução Normativa ${ }^{\circ} 37$ de 31 de outubro de 2000. Diário Oficial da República Federativa do Brasil, Brasília, 2000.

COSTA, R. G. et al. Influência do alimento na produção e qualidade do leite de cabra. Revista Brasileira de Zootecnia, v. $38, \mathrm{n}^{\circ}$ especial, p. 307-321, 2009.

EGITO, A. S. et al. Método eletroforético rápido para detecção da adulteração do leite caprino com leite bovino. Arquivo Brasileiro de Medicina Veterinária e Zootecnia, v. 58, n. 5, p. 932-939, 2006.

EIFERT, E. C. et al. Perfil de ácidos graxos do leite de vacas alimentadas com óleo de soja e monensina do início da lactação. Revista Brasileira de Zootecnia, v. 35, n. 1, p. 219228, 2006. 
EL-AGAMY, E. I. The challenge of cow milk protein allergy. Small Ruminant Research, v. 68, n. 1-2, p. 64-72, 2007.

EMBRAPA. Empresa Brasileira de Pesquisa Agropecuária. Caprinos \& Ovinos em Revista. Sobral: EMBRAPA, 2013.

ESPEJO-CARPIO, F. J. et al. Angiotensin I-converting enzyme inhibitory activity of enzymatic hydrolysates of goat milk protein fractions. International Dairy Journal, v. 32, n. 2, p. 175-183, 2013.

FAO. Food and Agriculture Organization of the United Nations. FAOSTAT. Disponível em: <http://faostat3.fao.org/>. Acesso em: 03 jun. 2014.

GOMEZ-RUIZ, J. A. et al. Quantitative determination of alfa-s2 and alfa-s1-casein in goat's milk with different genotypes by capillary electrophoresis. Journal of Chromatography A, v. 1054, n. 1-2, p. 279284, 2004.

GONÇALVES, A. L. et al. Avaliação de sistemas de produção de caprinos leiteiros na região Sudeste do Brasil. Revista Brasileira de Zootecnia, v. 37, n. 2, p. 366-376, 2008.

HOSAM, T. Effects of varying levels of protected fat on performance of Shami goats during early and mid lactation. Turkish Journal of Veterinary and Animal Sciences, v. 35, n. 2, p. 67-74, 2011.

Instituto Brasileiro de Geografia e Estatística (IBGE). SIDRA. Disponível em: $<$ http:// www.sidra.ibge.gov.br>. Acesso em: 03 jun. 2014.

JACOPINI, L. A. et al. Leite de cabra: características e qualidades. Revista ACTA Tecnológica, v. 6, n. 1, p. 168-180, 2011.
LI, Z. et al. Purification and identification of five novel antioxidant peptides from goat milk casein hydrolysates. Journal of Dairy Science, v. 96, n. 7, p. 4242-4251, 2013.

MADUREIRA, A. R. et al. Bovine whey proteins - overview on their main biological properties. Food Research International, v. 40, n. 10, p. 1197-1211, 2007.

MAIA, F. J. et al. Inclusão de fontes de óleo na dieta de cabras em lactação: produção, composição e perfil dos ácidos graxos do leite. Revista Brasileira de Zootecnia, v. 35, n. 4, p. 1504-1513, 2006.

MIGLIETTA, A. et al. Conjugated linoleic acid induces apoptosis in MDA-MB-231 breast cancer cells through ERK/MAPK signaling and mitochondrial pathway. Cancer Letters, v. 234, n. 2, p. 149-157, 2006.

PARK, Y. W. Goat milk - chemistry and nutrition. In: PARK, Y. W.; HAENLEIN, G. F. W. Handbook of Milks of Non Bovine Mammals. England: Blackwell Publishing, 2006. p. 34-58.

PARK, Y. W. et al. Physico-chemical characteristics of goat and sheep milk. Small Ruminant Research, v. 68, n. 1-2, p. 88-113, 2007.

PEREIRA, G. F. et al. Perfil de ácidos graxos no leite de cabras alimentadas com níveis crescentes de feno de flor-de-seda. Revista Caatinga, v. 22, n. 3, p. 206-210, 2009.

PEREIRA, R. A. G. et al. Physicochemical and sensory characteristics of milk from goats supplemented with castor or licuri oil. Journal of Dairy Science, v. 93, n. 2, p. 456-462, 2010.

PHELAN, M. et al. Casein-derived bioactive peptides: biological effects, industrial 
uses, safety aspects and regulatory status. International Dairy Journal, v. 19, n. 11, p. 643-654, 2009.

QUEIROGA, R. C. R. E. et al. Influência do Manejo do Rebanho, Condições Higiênicas da Ordenha e Fase de Lactação na composição Química do Leite de Cabras Saanen. Revista Brasileira de Zootecnia, v. 36, n. 2, p. 430437, 2007.

RAYNAL-LJUTOVAC, K. et al. Composition of goat and sheep milk products: An update. Small Ruminant Research, v. 79, n. 1, p. 57-72, 2008.

RIBEIRO, A. C.; RIBEIRO, S. D. A. Specialty products made from goat milk. Small Ruminant Research, v. 89 , n. 2-3, p. 225233, 2010.

RONCADA, P. et al. Farm animal milk proteomics. Journal of Proteomics, v. 75, n. 14, p. 4259-4274, 2012.

SALTER, A. M.; TARLING, E. J. Regulation of gene transcription by fatty acids. Animal, v. 4, p. 1314-1320, 2007.

SANTILLO, A. et al. Role of indigenous enzymes in proteolysis of casein in caprine milk. International Dairy Journal, v. 19, n. 11, p. 655-660, 2009.

SANTOS, K. M. O. et al. Probiotic caprine Coalho cheese naturally enriched in conjugated linoleic acid as a vehicle for Lactobacillus acidophilus and beneficial fatty acids. International Dairy Journal, v. 24, n. 2, p. 107-112, 2012.

SANTOS, T. D. R. et al. Physical, chemical and sensory characteristics of cream goat cheese produced with Saanen and Alpine milk. International Journal of Engineering Research \& Science, v. 2, n. 2, p. 102-111, 2016.

SANZ SAMPELAYO, M. R. et al. Influence of type of diet on the fat constituents of goat and sheep milk. Small Ruminant Research, v. 68, n. 1-2, p. 42-63, 2007.

SGARBIERI, V. C. Revisão: Propriedades Estruturais e Físico-Químicas das Proteínas do Leite. Brazilian Journal of Food Technology, v. 8, n. 1, p. 43-56, 2005.

SHEEHAN, J. J. et al. Effect of partial substitution of bovine for caprine milk on the compositional, volatile, non-volatile and sensory characteristics of semi-hard cheeses. International Dairy Journal, v. 19, n. 9, p. 498-509, 2009.

SILVA, G. L. S. et al. Consumo, digestibilidade e produção de cabras leiteiras alimentadas com dietas contendo diferentes fontes de lipídios. Acta Scientiarum. Animal Sciences, v. 32, n. 1, p. 47-53, 2010.

SLAČANAC, V. et al. Nutritional and therapeutic value of fermented caprine milk. International Journal of Dairy Technology, v. 63, n. 2, p. 171-189, 2010.

VIEITEZ, I. et al. Composition of fatty acids and triglycerides in goat cheeses and study of the triglyceride composition of goat milk and cow milk blends. Journal of Food Composition and Analysis, v. 48, n. 1, p. 95-101, 2016.

VILLALOBOS, C. A. Aspectos nutricionales de la leche de cabra (Capra hircus) y sus variaciones em el proceso agroindustrial. Agronomía Mesoamericana, v. 16, n. 2, p. 239-252, 2005. 